Research Article

\title{
Rake Angle Effect on a Machined Surface in Orthogonal Cutting of Graphite/Polymer Composites
}

\author{
Dayong Yang $(\mathbb{D}$, Zhenping Wan $(\mathbb{D}$, Peijie Xu, and Longsheng Lu \\ School of Mechanical and Automotive Engineering, South China University of Technology, Guangzhou 510640, China \\ Correspondence should be addressed to Dayong Yang; ydy425@126.com
}

Received 9 April 2018; Accepted 24 May 2018; Published 19 June 2018

Academic Editor: Massimiliano Barletta

Copyright (C) 2018 Dayong Yang et al. This is an open access article distributed under the Creative Commons Attribution License, which permits unrestricted use, distribution, and reproduction in any medium, provided the original work is properly cited.

Graphite and its composites have been widely used in various industrial fields. It has been generally accepted that, for positive rake angles, there is a significant increase in tension stress at the cutting zone during the machining of brittle materials, and cracks occur and spread easily, degrading the quality of the machined surface quality. However, it is found in this study that positive rake angles can improve the machined surface finish during the orthogonal cutting of graphite/polymer composites. Better machined surface finish is obtained for a larger rake angle. A finite element model is developed to reveal the mechanism of influence of the positive rake angle on the machined surface. Based on the effective stress field obtained from finite element analysis, it can be predicted that the crack initiates at the tool tip, subsequently propagates downward and forward, and later spreads gradually toward the free surface of the workpiece. A larger rake angle can promote crack propagation far from the machined surface. The crack initiation and propagation laws are validated by the edge-indentation experiments. In addition, the cutting force at various rake angles is investigated.

\section{Introduction}

Graphite and its composites (G/GCs) have been increasingly used in the fabrication of various precision parts such as biomedical implants [1], thermal sinks [2], bipolar plates of fuel cells [3], electrical discharge machining (EDM) electrodes [4], semiconductor jigs, pile cores, and mechanical seals [5]. G/GCs have abrasive and brittle characters, and the material in cutting zone undergoes localized fractures rather than plastic deformation during machining [6]. Moreover, the crack initiation and propagation laws of G/GCs, such as graphite/polymer composites, are unique and distinct from other brittle materials [7]. Hence, the machining mechanism of G/GCs is different from that of the other brittle materials, for example, structural ceramics [8] and other types of composite materials, such as carbon/epoxy composites [9] and carbon fiber-reinforced polymer/plastic [10]. Therefore, the machining of G/GCs has attracted considerable attention.

To date, the investigations on the machining of G/GCs mainly focus on the tool wear and machined surface quality. Graphite is extremely abrasive due to the bond strength between individual carbon molecules [11]. Therefore, in graphite machining, randomly oriented graphite aggregates lead to severe tool wear due to the abrasive character of graphite [12], and different process parameters will result in different tool wear modes. When the hot-filament chemical vapor-deposited and time-modulated chemical vapor-deposited diamondcoated tool inserts were used for the machining of graphite, the main wear modes were crater wear and notching resulting from the action of the graphite powder coming into contact with and sliding against the tool surface during machining [6]. During the high-speed milling of graphite using an AlTiNcoated carbide micro-end mill, the flank wear is the dominant wear pattern in the steady wear stage [13]. When the graphite electrodes were turned by microcrystalline and nanocrystalline diamond-coated $\mathrm{Si}_{3} \mathrm{~N}_{4}$ ceramic inserts, the main tool wear mode was abrasion-induced by the powdery graphite [12]. According to the studies of Lei et al. [14] and Hashimoto et al. [15], the deposition of microcrystalline diamond films on cocemented tungsten carbide micro-drills and the introduction of nitrogen into the cutting area are effective methods for extending tool life. On the other hand, the investigations conducted by Wan et al. [7] indicated that there were a huge number of tiny concavities on the machined surface of graphite/polymer composites. Hence, it is difficult to obtain a good surface finish because graphite is a brittle 


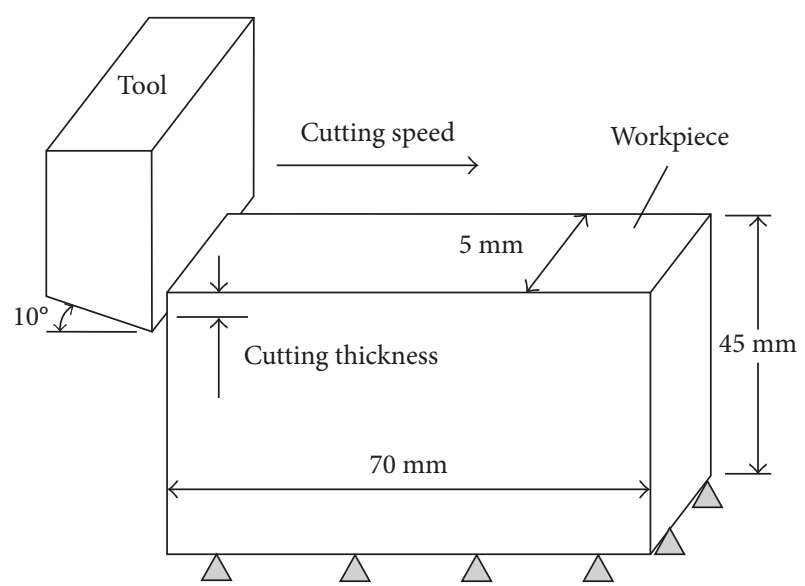

FIgURE 1: Schematic diagram of orthogonal cutting experiments.

material, and brittle fracture is the main characteristic during graphite machining [16]. To obtain a good surface finish, great efforts have been conducted. Wang et al. [17] found that a smoother surface could be achieved with a small feed per tooth in the high-speed milling of a graphite electrode. The experimental results presented by Zhou et al. [18] showed that the surface roughness of the machined surface increased clearly with the depth of cut increasing in the orthogonal cutting of graphite. Huo et al. [11] found that the feed rate has the most significant influence on surface roughness, and the surface roughness is not sensitive to cutting speed on the micro-milling of fine-grained graphite. The statistical analysis also showed that the surface roughness decreased with a low feed rate [19]. Experimental design methods [20], artificial neural networks [21], and the gray relational analysis method [22] were used to optimize the machining parameters for highpurity graphite in the end milling process. Additionally, Bajpai and Singh investigated the orthogonal micro-grooving of anisotropic pyrolytic carbon [23] and established a finite element model to understand the mechanics of material removal in the plane of transverse isotropy of pyrolytic carbon [24].

From the above literature survey, little work has been reported on the effect of the tool rake angle on the machined surface quality during graphite/polymer composite machining. This paper investigates the influence of the tool rake angle on the machined surface finish during the orthogonal cutting of graphite/polymer composites. To reveal the mechanism of influence of a positive tool rake angle on the machined surface finish, the effective stress field of the cutting zone was determined out by finite element analysis, and then, the crack initiation and propagation path in the cutting zone were predicted based on the effective stress field. The laws of crack initiation and propagation were verified by edge-indentation experiments, which are effective methods for the study of the material removal mechanism during brittle material cutting $[6,25,26]$. In addition, the effect of the tool rake angle on the cutting force was investigated.

\section{Experimental Methodologies}

2.1. Experimental Conditions of Orthogonal Cutting. Dry orthogonal cutting experiments were conducted on planer
BC6063B. The dimensions of the workpiece are $70 \mathrm{~mm} \times$ $45 \mathrm{~mm} \times 5 \mathrm{~mm}$. A superhard high-speed steel tool with the clearance angle of $10^{\circ}$ and different rake angles is used to machine the workpiece at the cutting speed of $6 \mathrm{~m} / \mathrm{min}$. The cutting thicknesses are $0.2 \mathrm{~mm}$ and $0.4 \mathrm{~mm}$. A schematic diagram of the orthogonal cutting experiments is shown in Figure 1.

The graphite/polymer composites used in this study are a powder mixture of coke and natural graphite added to a binder. The paste is first homogenized and placed in a mold and then is sufficiently compacted. The material is then baked slowly at high temperature. The physical and mechanical properties of the graphite/polymer composites are shown in Table 1.

2.2. Edge-Indentation Experimental Setup. The edge-indentation experiments are conducted using a universal material testing machine (CMT5105). A schematic drawing of the edgeindentation experiments is shown in Figure 2, with the indenter positioned on the edge of the graphite/polymer composite specimen. The edge-indentation surface of the specimen is polished until no cracks can be observed in order to eliminate the influence of tiny cracks on crack initiation and propagation. The indenter can rotate adaptively to ensure welldistributed pressure on the indentation surface. The dimensions of the graphite/polymer composite specimen are $70 \mathrm{~mm} \times$ $45 \mathrm{~mm} \times 5 \mathrm{~mm}$. All specimens are indented at the constant speed of $0.5 \mathrm{~mm} / \mathrm{min}$.

It can be seen from Figure 2 that the edge indentation is similar to orthogonal cutting. In Figure $2, \gamma_{\mathrm{s}}$ is the rake angle of the indenter, $h_{\mathrm{D}}$ is the edge-indentation thickness, and $P$ is the normal load imposed on the indenter. The indenter is similar to a cutting tool with the rake angle of $\gamma_{\mathrm{s}}$ and clearance angle of $0^{\circ}$, and $h_{\mathrm{D}}$ is the cutting thickness. Therefore, the laws of crack initiation and propagation obtained from the edgeindentation experiments can be applied to validate the predicted crack initiation and propagation rules for the graphite/polymer composite orthogonal cutting process.

\section{Effect of Rake Angle on Machined Surface Finish}

Figure 3 shows the machined surface roughness Ra obtained at different rake angles for the cutting thicknesses of $0.2 \mathrm{~mm}$ and $0.4 \mathrm{~mm}$. It can be seen from Figure 3 that the surface roughness $\mathrm{Ra}$ is largest when the rake angles are $0^{\circ}$ and $5^{\circ}$, and the surface roughness $\mathrm{Ra}$ decreases gradually with either an increase or decrease in the rake angle. The entire curve can be fitted by a parabola. The fact that a negative rake angle can reduce the surface roughness conforms to the long-held notion that the compressive stresses induced by a negative rake angle can weaken the breaking of the material, resulting in improved surface qualities. However, the fact that a positive rake angle can also reduce the surface roughness and improve the machined surface qualities conflicts with the long-held notion that flaking due to tensile stresses induced by a positive rake angle damages the machined surface in the machining of brittle materials.

Figure 4 shows the surface morphologies machined at different rake angles for the cutting thickness of $0.2 \mathrm{~mm}$. Due to the 
TABLE 1: Mechanical properties of graphite/polymer composites.

\begin{tabular}{lcccccc}
\hline Properties & $\begin{array}{c}\text { Density } \\
\left(\mathrm{g} / \mathrm{cm}^{3}\right)\end{array}$ & $\begin{array}{c}\text { Hardness } \\
(\text { shores })\end{array}$ & $\begin{array}{c}\text { Tensile strength } \\
(\mathrm{MPa})\end{array}$ & $\begin{array}{c}\text { Compressive strength } \\
(\mathrm{MPa})\end{array}$ & $\begin{array}{c}\text { Modulus of elasticity } \\
(\mathrm{GPa})\end{array}$ & $\begin{array}{c}\text { Porosity } \\
(\%)\end{array}$ \\
\hline Parameter & 1.9 & 75 & 17.3 & 107.2 & 15.9 \\
\hline
\end{tabular}

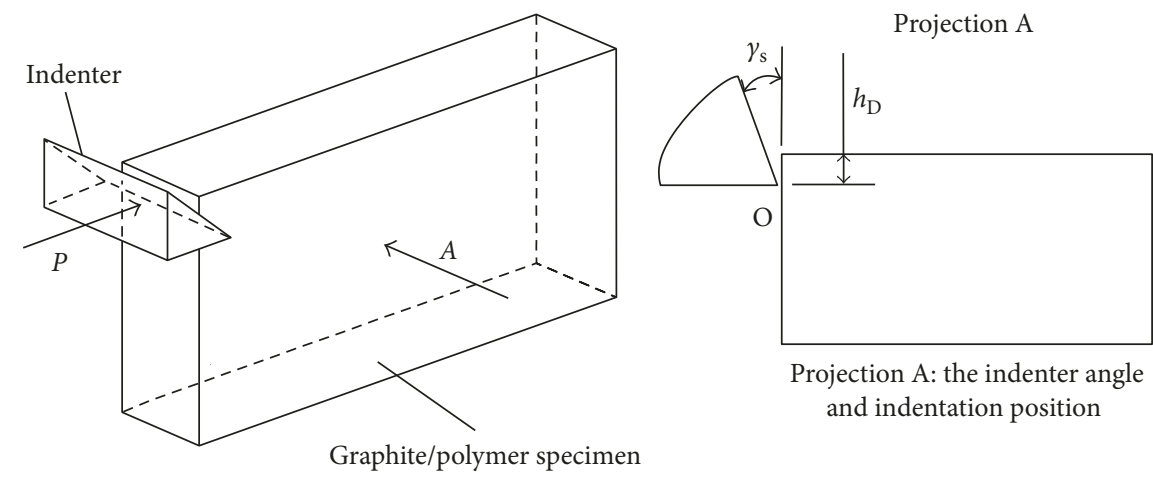

FIGURE 2: Schematic drawing of edge-indentation experiment.

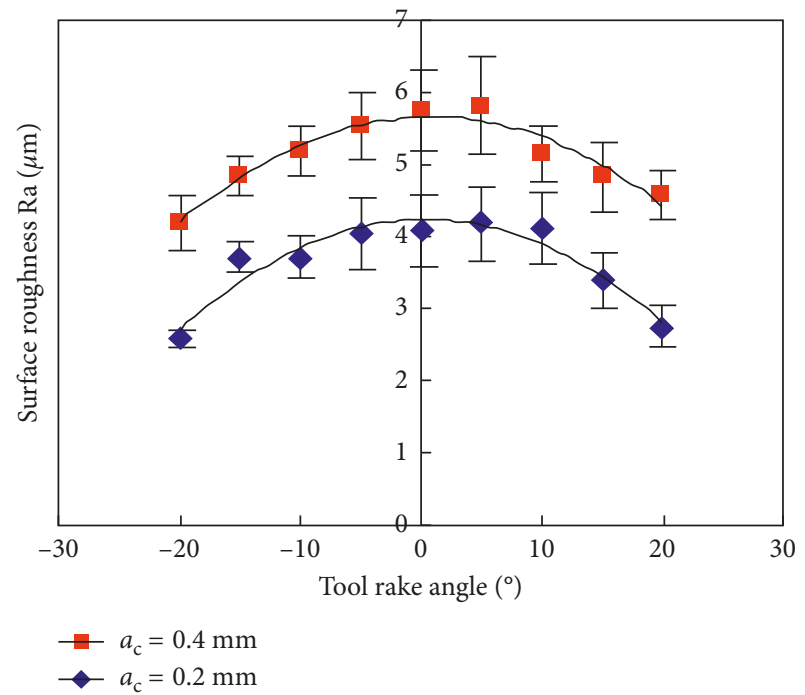

Figure 3: Machined surface roughness of graphite/polymer composites at different rake angles.

breaking of the surface material, many concavities are observed on the machined surface. Furthermore, the largest concavities are formed on the surface machined at the rake angle of $0^{\circ}$. With increased or decreased of rake angles, the concavities gradually decrease. It is suggested that, with increasing rake angle, the machined surface qualities are improved for positive rake angles during graphite/polymer composite orthogonal cutting.

\section{Mechanism of Influence of a Positive Rake Angle on a Machined Surface}

The discussion in this section focuses only on the mechanism of influence of a positive rake angle on the machined surface finish because the mechanism of influence of a negative rake angle on machined surface qualities has been studied thoroughly. The crack initiation and propagation at the cutting

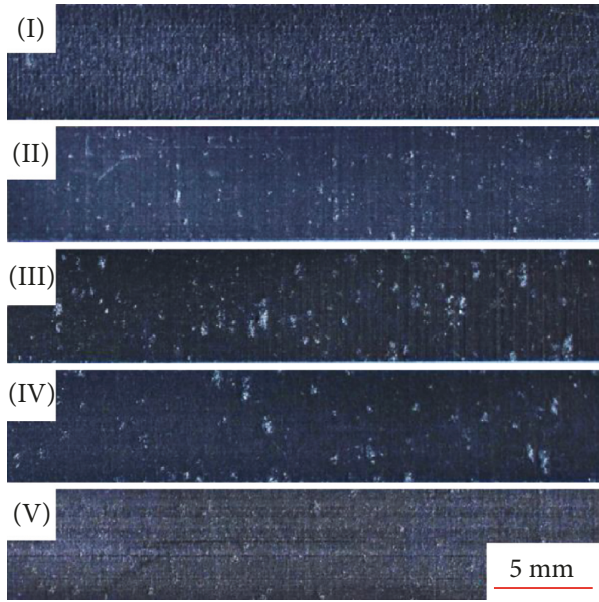

FIGURE 4: Surface morphologies machined at cutting thickness of $0.2 \mathrm{~mm}$ and different rake angles: (I) $-20^{\circ}$, (II) $-10^{\circ}$, (III) $0^{\circ}$, (IV) $10^{\circ}$, and $(\mathrm{V}) 20^{\circ}$.

zone are the main processes during graphite machining that result in large amounts of crack and concavity formation on the machined surface. Hence, the determination of the rules that govern crack initiation and propagation is highly important for understanding the mechanism of influence of a positive rake angle on the machined surface.

4.1. Effective Stress Field of the Cutting Zone. During graphite/ polymer cutting, surface materials are removed through the brittle fracture of the material. The brittle fracture of material is determined by the effective stress field of the cutting zone. Hence, the analysis of the effective stress field of the cutting zone is helpful for understanding the material removal mechanism.

4.1.1. Fracture Criterion of Material. According to Paul and Mirandy's theory [27], if $\sigma_{\mathrm{III}} / \sigma_{\mathrm{b}}<\left(1-N^{2}\right)$, the fracture criterion for the three-dimensional stress state is given by 


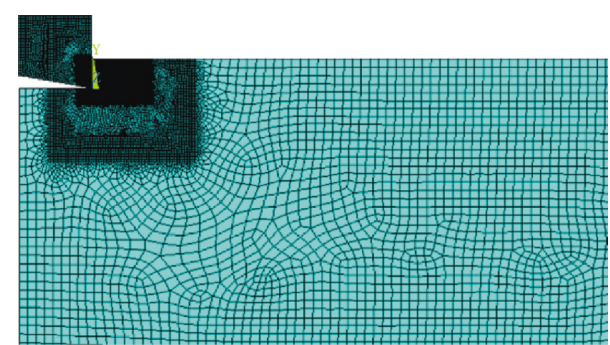

FIGURE 5: Mesh models of graphite composite orthogonal cutting.

$$
\sigma_{\text {eff }}=\frac{N\left(\sigma_{\text {I }}+\sigma_{\text {III }}\right)+2 \sqrt{N^{2} \sigma_{\mathrm{I}} \sigma_{\text {III }}+\left(\sigma_{\mathrm{I}}+\sigma_{\text {III }}\right)^{2}}}{N\left(4-N^{2}\right)} .
$$

If $\sigma_{\mathrm{III}} / \sigma_{\mathrm{b}} \geq\left(1-N^{2}\right)$, the fracture criterion for the threedimensional stress state is

$$
\sigma_{\text {eff }}=\sigma_{\mathrm{I}},
$$

where $\sigma_{\text {eff }}$ is the effective stress; $\sigma_{\text {I }}$ and $\sigma_{\text {III }}$ are the maximal principal stress and minimum principal stress, respectively; and $\sigma_{\mathrm{b}}$ is the tension strength. $N$ is a constant determined by the following equation:

$$
N=\sqrt{2+\frac{\sigma_{\mathrm{bc}}}{\sigma_{\mathrm{b}}}-2 \sqrt{1+\frac{\sigma_{\mathrm{bc}}}{\sigma_{\mathrm{b}}}}}
$$

where $\sigma_{\mathrm{bc}}$ is the compressive strength.

4.1.2. Finite Element Modeling. ANSYS explicit dynamics are used to calculate the effective stress field of the cutting zone. The sketch of the graphite/polymer composite orthogonal cutting is shown in Figure 1. In finite element modeling, the dimensions of the workpiece are $50 \mathrm{~mm} \times 25 \mathrm{~mm} \times 5 \mathrm{~mm}$, and the properties of the workpiece material are described in Table 1 . The clearance angle of the tool is $10^{\circ}$, and the cutting thickness is $2 \mathrm{~mm}$. The workpiece is fixed in all directions, and the cutting tool is modeled as a rigid body that moves forward at the speed of $6 \mathrm{~m} / \mathrm{min}$. The interaction between the chip and the tool can be modeled as sliding frictional behavior. The friction coefficient is defined as $\mu=F_{\mathrm{t}} / F_{\mathrm{n}}$, where $F_{\mathrm{t}}$ is the tangential force acting on the rake face and $F_{\mathrm{n}}$ is the normal force acting on the rake face. Based on the cutting force measurements, the friction coefficient is assumed to be 0.5 . In the graphite cutting process, high temperature is almost nonexistent. The orthogonal cutting is simplified as two-dimensional cutting, and a total of 28,300 quadrilateral meshes are used to model the workpiece, as shown in Figure 5. A very fine mesh density is defined at the contact zone of the tool tip and the workpiece in order to obtain fine process output distributions.

\subsubsection{Effective Stress Field and Crack Initiation and Prop-} agation Prediction. The effective stress contours of the cutting zone during the cutting process are shown in Figure 6 when the rake angles of cutting tool are $0^{\circ}, 10^{\circ}$, and $20^{\circ}$. Figures 6(a)-6(c) show snapshots when the effective stresses in the vicinity of the tool tip just reach or approach the tension strength. In the effective stress field, the crack initiates at the point where the stress reaches the tension strength and propagates along the direction of the minimum stress gradient. In Figure 6, the curve $c$ denotes the direction of the minimum stress gradient. Thus, the curve $c$ also indicates the crack propagation path in the cutting zone. It can be seen from Figure 6 that the crack initiates at the tool tip and then propagates downward and forward, subsequently spreading gradually upward until it intersects the free surface of the workpiece. Therefore, the block of the workpiece material surrounded by the crack is removed by brittle fracture, and a concavity forms on the machined surface. By comparing Figures 6(a) and 6(b), it can be easily seen that when the rake angle of the tool is $10^{\circ}$, the crack $c$ spreads toward the free surface of the workpiece soon after its first appearance, and a small concavity remains. When the rake angle is $0^{\circ}$, the crack propagation path is long, and a large concavity forms. As shown in Figure 6(c), the crack hardly propagates downward, and in this case, a good surface finish can be obtained. Therefore, a large positive rake angle can facilitate crack spreading toward the free surface of the workpiece and improves the machined surface qualities.

\subsection{Validation of Crack Initiation and Propagation Rules.} The rules governing crack initiation and propagation predicted from the effective stress field of the cutting zone can elucidate the mechanism of influence of the positive rake angle on the machined surface qualities. However, the predictions should be verified by experiments. This section investigates the rules governing crack initiation and propagation during graphite/ polymer orthogonal cutting through edge-indentation experiments.

4.2.1. Crack Initiation and Propagation Path. Figure 7 shows the crack initiation and propagation path under the action of an indenter with rake angles $\left(\gamma_{\mathrm{s}}\right)$ of $5^{\circ}, 10^{\circ}$, and $20^{\circ}$ when $h_{\mathrm{D}}$ is $2 \mathrm{~mm}$. With the increase in the normal load $P$, no crack occurs at the beginning of loading. At this point, a notch forms at the contact of the indenter and graphite/polymer specimen, as shown in Figure $7(\mathrm{a})$. The crack initiates suddenly and propagates rapidly when the normal load increases to a critical value. In this case, the propagation of the crack will terminate if the load can be removed quickly. However, there is usually not enough time to remove the normal load before the crack reaches the free surface. Therefore, a large block of graphite surrounded by the crack sheds, as shown in Figure 7, where the crack spreads downward in the direction of the indentation in the initial stage and then propagates gradually toward the free surface of specimen. The propagation path of the crack is close to an arc shape. The crack spreads farther from the inside of the specimen with the increase of rake angle of the indenter. That is, a large rake angle can facilitate the crack spreading further toward the free surface of the workpiece if the indenter is considered as a cutting tool. When $\gamma_{\mathrm{s}}$ is $20^{\circ}$, the formed crack hardly damages the machined surface, as shown in Figure 7(c). This outcome suggests that the experimental results are in good agreement with the predictions of crack initiation and propagation. Furthermore, 


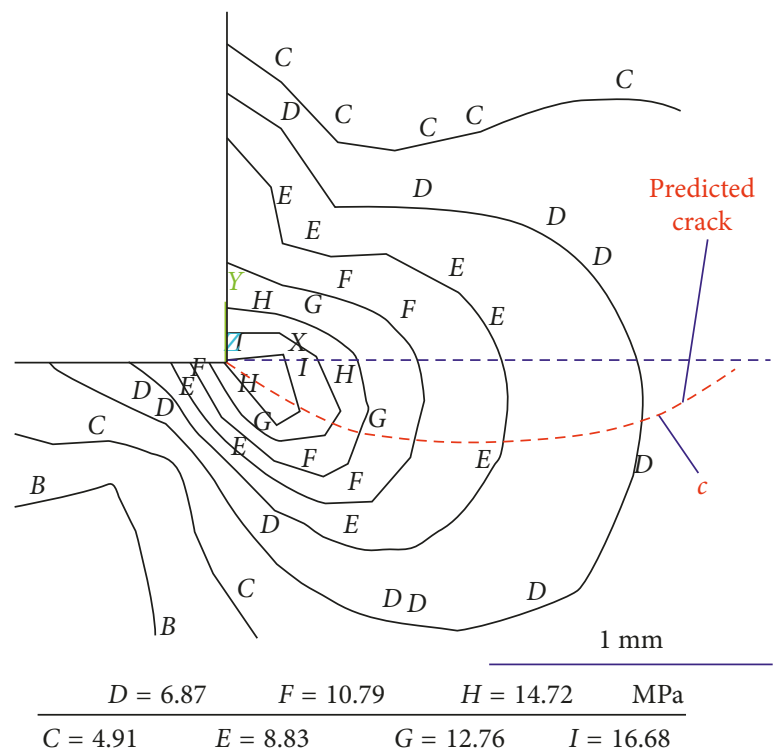

(a)

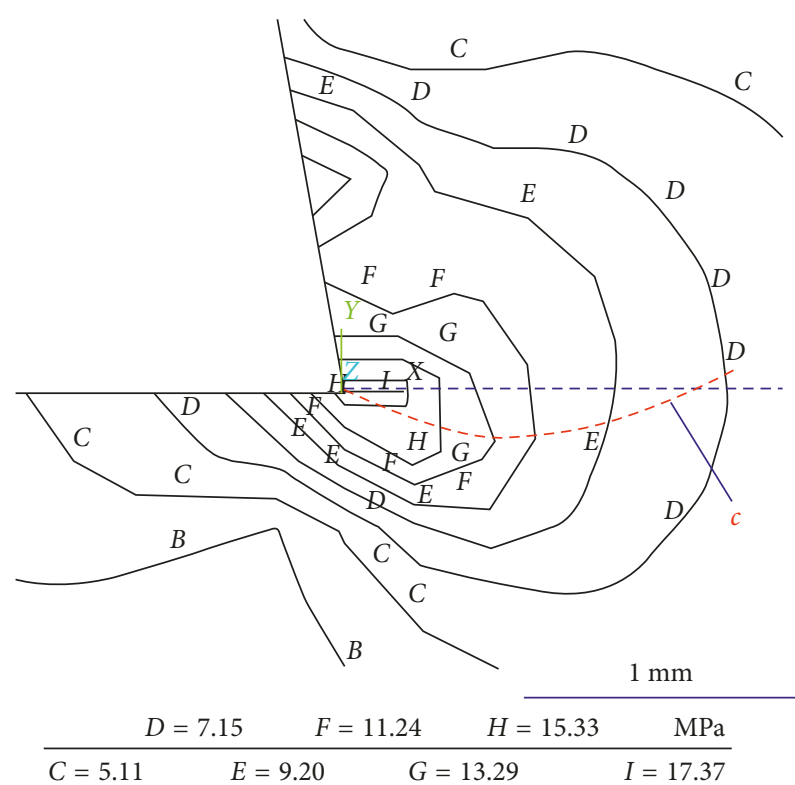

(b)

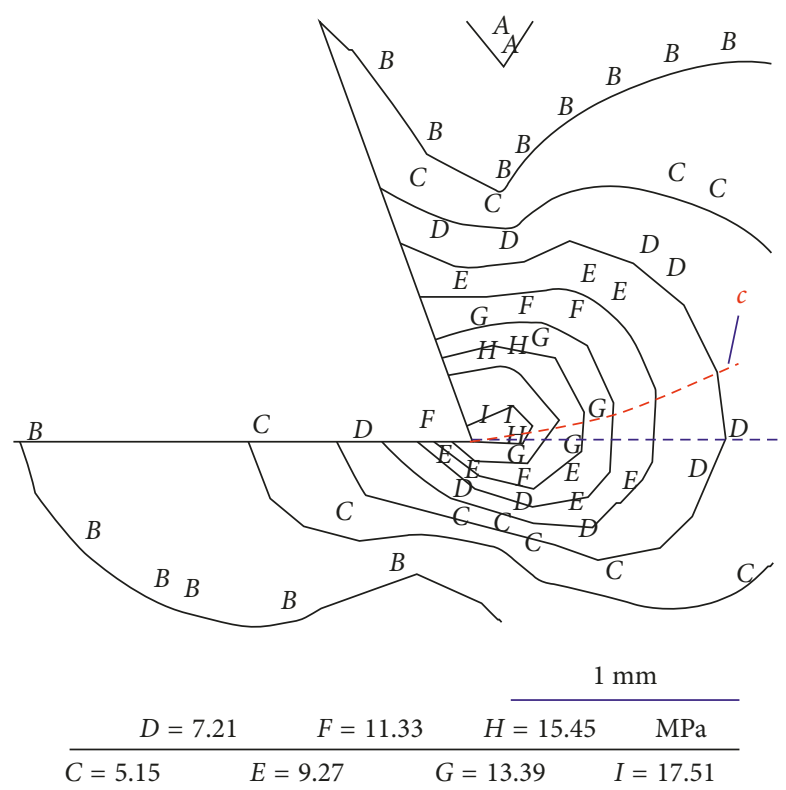

(c)

FIGURE 6: Effective stress contours in cutting zone and predicted crack propagation paths (the stresses in the vicinity of the tool tip just reach tension strength) at rakes angles of (a) $0^{\circ}$, (b) $10^{\circ}$, and (c) $20^{\circ}$.

the crack propagation path in the graphite/polymer composite is different from the glass crack propagation path, which shows a rectilinear configuration in edge-indentation experiments. More importantly, a smaller rake angle leads to the glass crack propagating farther away from the machined surface. Hence, the rules governing the crack propagation of graphite/polymer composites are in contrast to the laws of glass crack propagation. Thus, graphite/polymer composite machining has its own unique laws that are unlike those of glass cutting.

\subsubsection{Relationship of the Rake Angle of the Indenter to Crack} Propagation Path. According to the above experimental results, the crack initiates at the contact of the indenter and specimen and propagates in an arc-shaped path. As a result, a concavity forms. Thus, the initial angle of crack propagation $\theta$, concavity depth $c_{\mathrm{d}}$, and concavity width $c_{\mathrm{w}}$ are used to describe the crack propagation path, as shown in Figure 8. Figure 9 depicts the changing trend of the width and depth of concavities with the rake angle of the indenter at the edgeindentation thickness of $2 \mathrm{~mm}$. The width and depth of the concavities decrease as the rake angle of the indenter increases. Larger rake angle of indentation leads to smaller size of the concavities. Furthermore, the concavity depth decreases linearly as the rake angle of the indenter increases, 


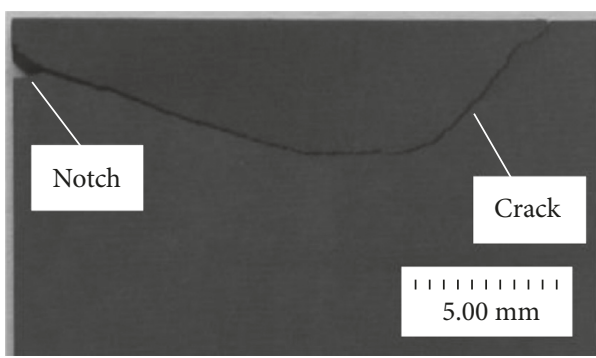

(a)

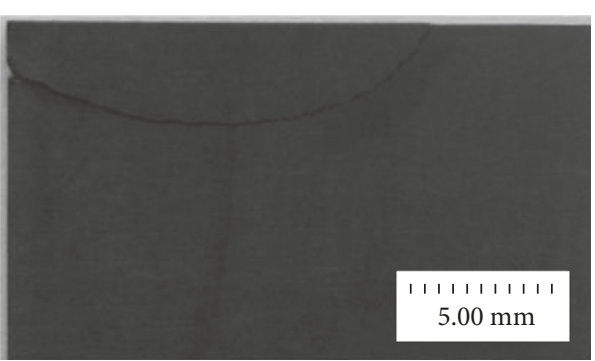

(b)

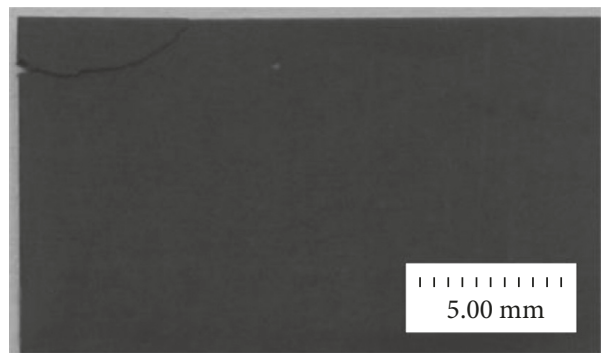

(c)

Figure 7: Crack initiation and propagation paths at different rake angles of indenter $\left(h_{\mathrm{D}}=2 \mathrm{~mm}\right)$ : (a) $\gamma_{\mathrm{s}}=5^{\circ}$, (b) $\gamma_{\mathrm{s}}=10^{\circ}$, and $(\mathrm{c}) \gamma_{\mathrm{s}}=20^{\circ}$.

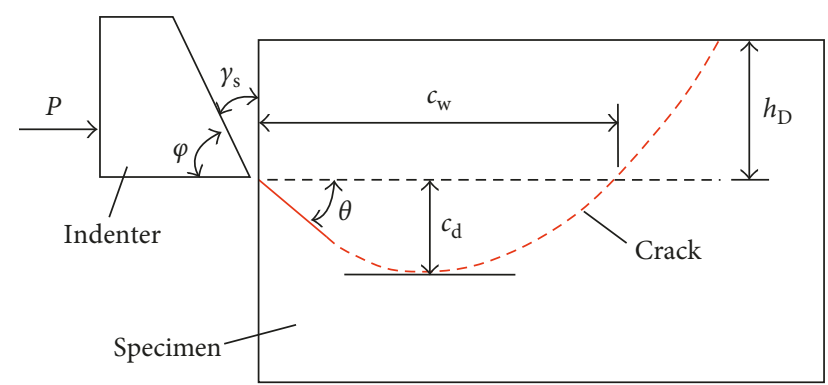

Figure 8: Parameters of crack initiation and propagation path.

while the largest width of the concavity formed by the action of the indenter is obtained for the rake angle of $5^{\circ}$. This outcome occurs because the indented specimen is vulnerable to collapse (as shown in Figure 10) when the rake angle of the indenter is $0^{\circ}$, and once the material of the indentation surface is disintegrated, the real edge-indentation thickness will be reduced. Thus, the concavity width produced at indenter rake angle of $0^{\circ}$ is even smaller than that produced at indenter rake angle of $5^{\circ}$, as shown in Figure 9. Consequently, the surface roughness obtained at rake angle of $5^{\circ}$ is largest as shown in Figure 3.

Figure 11 shows the dependence of the initial angle of crack propagation on the rake angle of the indenter. It can be seen from Figure 11 that the initial angles of crack propagation decrease linearly with increasing rake angle of the indenter. That is, the larger the rake angle of the indenter is, the smaller the initial angle of crack propagation. Thus, a large rake angle of the indenter can make the crack propagate farther away from the inside of the specimen. This outcome further confirms that a large rake angle of the cutting tool can improve the machined surface finish of graphite/polymer composites.

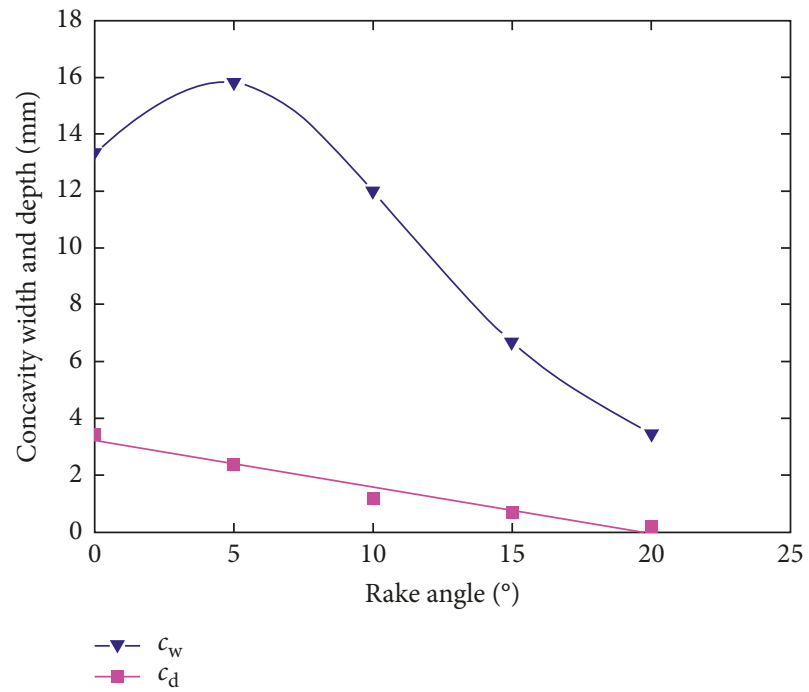

FIgURE 9: Width and depth of concavities at different rake angles of indenter $\left(h_{\mathrm{D}}=2 \mathrm{~mm}\right)$.

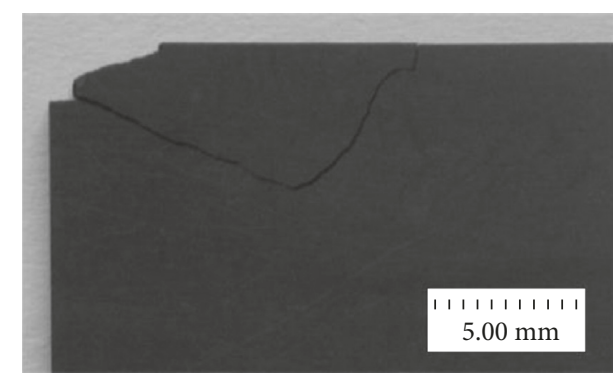

FIgURE 10: Crack initiation and propagation path formed at indenter rake angle of $0^{\circ}\left(h_{\mathrm{D}}=2 \mathrm{~mm}\right)$. 


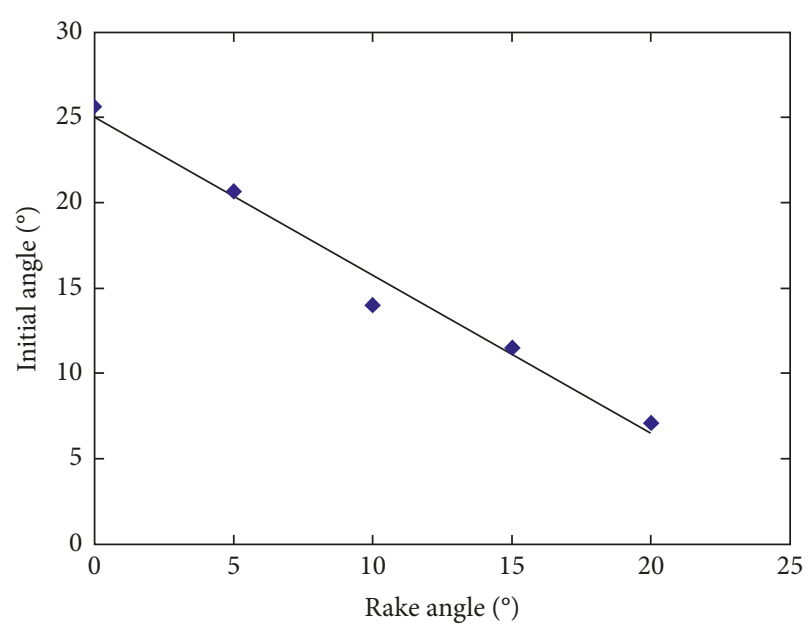

FIGURE 11: Initial angle of crack propagation at different indenter rake angles.

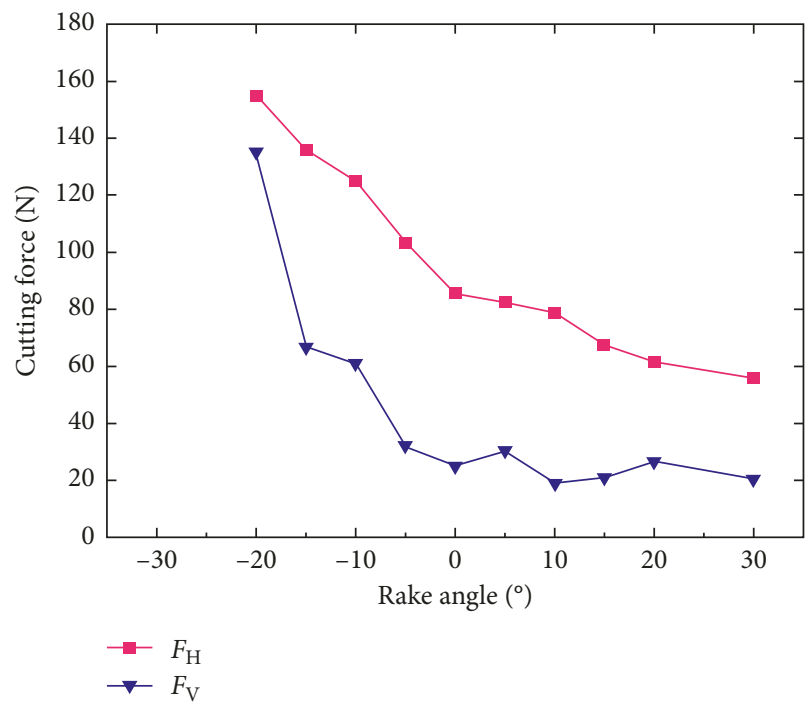

FIGURE 12: Cutting forces at different rake angles $(v=6 \mathrm{~m} / \mathrm{min}$, $\left.a_{\mathrm{c}}=0.4 \mathrm{~mm}\right)$.

\section{Cutting Force at a Different Rake Angle}

The cutting force was measured by a Kistler dynamometer. The horizontal cutting forces $F_{\mathrm{H}}$ and vertical cutting forces $F_{\mathrm{V}}$ at different tool rake angles are shown in Figure 12 for the cutting speed $v$ of $6 \mathrm{~m} / \mathrm{min}$ and the depth of cut $a_{\mathrm{c}}$ of $0.4 \mathrm{~mm}$. It can be observed from Figure 12 that the cutting force decreases with increasing rake angle regardless of whether the rake angle is negative or positive. Furthermore, the cutting force decreases dramatically with increasing rake angle when the rake angle is negative. When the rake angle is positive, the horizontal cutting force decreases with a small slope, and the vertical cutting force is almost invariable while the rake angle is increasing. Thus, it can be observed that there is a turning point in the variation curve of cutting force when the rake angle is $0^{\circ}$. Considering the influence of the rake angle on the machined surface finish and cutting force, it can be concluded that a positive rake angle that is higher than $5^{\circ}$ should be selected and used for the machining of graphite/polymer composites.

\section{Conclusions}

(1) When the rake angle during the graphite/polymer composite orthogonal cutting is between $0^{\circ}$ and $5^{\circ}$, the machined surface finish is the poorest, and the machined surface finish is improved with decreasing or increasing rake angle.

(2) The crack initiates at the tool tip, subsequently propagates downward and forward, and then spreads gradually toward the free surface of the workpiece, resulting in the removal of a block of graphite surrounded by the crack and the formation of a concavity on the machined surface. A large positive rake angle can facilitate crack propagation far away from the machined surface. Therefore, the concavities formed on the machined surface decrease. Thus, a large positive rake angle can improve the machined surface finish.

(3) The cutting force decreases with increasing rake angle. Furthermore, when the rake angle is negative, the cutting force decreases rapidly with increasing rake angle. When the rake angle is positive, the horizontal cutting force decreases slowly, while the vertical cutting force remains almost constant with increasing rake angle.

(4) Considering the machined surface finish and cutting force, it is better to use a positive rake angle greater than $5^{\circ}$ to machine graphite/polymer composites.

\section{Notations}

$a_{\mathrm{c}}: \quad$ Cutting depth $(\mathrm{mm})$

$c_{\mathrm{d}}$ : Concavity depth $(\mathrm{mm})$

$c_{\mathrm{w}}$ : Concavity width $(\mathrm{mm})$

$F_{\mathrm{H}}$ : Horizontal cutting force $(\mathrm{N})$

$F_{\mathrm{n}}$ : Normal force $(\mathrm{N})$

$F_{\mathrm{t}}$ : Tangential force $(\mathrm{N})$

$F_{\mathrm{V}}$ : Vertical cutting force $(\mathrm{N})$

$h_{\mathrm{D}}$ : Edge-indentation thickness $(\mathrm{mm})$

$N$ : Constant

$P$ : $\quad$ Normal load imposed on indenter (N)

$\gamma_{s}$ : Rake angle of indenter (degree)

$\theta$ : Initial angle of crack propagation (degree)

$\mu$ : Friction coefficient

$v$ : Cutting speed $(\mathrm{m} / \mathrm{min})$

$\sigma_{\mathrm{b}}$ : Tension strength $(\mathrm{MPa})$

$\sigma_{\mathrm{bc}}$ : Compressive strength $(\mathrm{MPa})$

$\sigma_{\text {eff: }}$ Effective stress $(\mathrm{MPa})$

$\sigma_{\mathrm{I}}: \quad$ Maximal principal stress $(\mathrm{MPa})$

$\sigma_{\text {III }}$ Minimum principal stress $(\mathrm{MPa})$.

\section{Data Availability}

The digital data used to support the findings of this study are available from the corresponding author upon request. 


\section{Conflicts of Interest}

The authors declare that there are no conflicts of interest regarding the publication of this paper.

\section{Acknowledgments}

This work is supported by the National Natural Science Foundation of China (no. 51775198) and the Science and Technology Project of Guangzhou, China (201804010182).

\section{References}

[1] V. Starý, L. Bačáková, J. Horník, and V. Chmelík, "Biocompatibility of the surface layer of pyrolytic graphite," Thin Solid Films, vol. 433, no. 1-2, pp. 191-198, 2003.

[2] T. C. Chang, S. Lee, Y. K. Fuh, Y.-C. Peng, and Z.-Y. Lin, "PCM based heat sinks of paraffin/nanoplatelet graphite composite for thermal management of IGBT," Applied Thermal Engineering, vol. 112, pp. 1129-1136, 2017.

[3] K. Kang, S. Park, A. Jo, K. Lee, and H. Ju, "Development of ultralight and thin bipolar plates using epoxy-carbon fiber prepregs and graphite composites," International Journal of Hydrogen Energy International Journal of Hydrogen Energy, vol. 42, no. 3, pp. 1691-1697, 2017.

[4] M. Zeis, "Deformation of thin graphite electrodes with high aspect ratio during sinking electrical discharge machining," CIRP Annals, vol. 66, no. 1, pp. 185-188, 2017.

[5] M. Masuda, Y. Kuroshima, and Y. Chujo, "The machinability of sintered carbons based on the correlation between tool wear rate and physical and mechanical properties," Wear, vol. 195, pp. 178-185, 1996.

[6] G. Cabral, P. Reis, R. Polini et al., "Cutting performance of time-modulated chemical vapour deposited diamond coated tool inserts during machining graphite," Diamond and Related Materials, vol. 15, no. 10, pp. 1753-1758, 2006.

[7] Z. Wan, D. Yang, L. Lu, J. Wu, and Y. Tang, "Mechanism of material removal during orthogonal cutting of graphite/ polymer composites," International Journal of Advanced Manufacturing Technology, vol. 82, no. 9-12, pp. 1815-1821, 2016.

[8] C. Nath, G. C. Lim, and H. Y. Zheng, "Influence of the material removal mechanisms on hole integrity in ultrasonic machining of structural ceramics," Ultrasonics, vol. 52, no. 5, pp. 605-613, 2012.

[9] H. Gao, Y. J. Bao, and Z. M. Feng, "A study of drilling unidirectional carbon/epoxy composites," International Journal of Abrasive Technology, vol. 4, no. 1, pp. 1-13, 2011.

[10] X. Wang, X. Shen, G. Yang, and F. Sun, "Evaluation of borondoped-microcrystalline/nanocrystal-line diamond composite coatings in drilling of CFRP," Surface and Coatings Technology, vol. 330, pp. 149-162, 2017.

[11] D. Huo, C. Lin, and K. Dalgarno, "An experimental investigation on micro machining of fine-grained graphite," International Journal of Advanced Manufacturing Technology, vol. 72, no. 5-8, pp. 943-953, 2014.

[12] F. A. Almeida, J. Sacramento, F. J. Oliveira, and R. F. Silva, "Micro- and nano-crystalline CVD diamond coated tools in the turning of EDM graphite," Surface and Coatings Technology, vol. 203, no. 3-4, pp. 271-276, 2008.

[13] L. Zhou, C. Y. Wang, and Z. Qin, "Tool wear characteristics in high-speed milling of graphite using a coated carbide micro endmill," Proceedings of the Institution of Mechanical
Engineers, Part B: Journal of Engineering Manufacture, vol. 223, no. 3, pp. 267-277, 2009.

[14] X. L. Lei, L. Wang, B. Shen, F. Sun, and Z. Zhang, "Effect of boron-doped diamond interlayer on cutting performance of diamond coated micro drills for graphite machining," $M a$ terials, vol. 6, no. 8, pp. 3128-3138, 2013.

[15] M. Hashimoto, K. Kanda, and T. Tsubokawa, "Reduction of diamond-coated cutting tool wear during graphite cutting," Precision Engineering, vol. 51, pp. 186-189, 2018.

[16] R. B. Schroeter, R. Kratochvil, and J. D. Gomes, "High-speed finishing milling of industrial graphite electrodes," Journal of Materials Processing Technology, vol. 179, no. 1-3, pp. 128$132,2006$.

[17] C. Y. Wang, L. Zhou, H. Fu et al., "High speed milling of graphite electrode with endmill of small diameter," Chinese Journal of Mechanical Engineering, vol. 20, no. 4, pp. 27-31, 2007.

[18] L. Zhou, C. Y. Wang, and Z. Qin, "Investigation of chip formation characteristics in orthogonal cutting of graphite," Materials and Manufacturing Processes, vol. 24, no. 12, pp. 1365-1372, 2009.

[19] O. S. López, A. R. González, and I. H. Castillo, "Statistical analysis of surface roughness of machined graphite by means of CNC milling," Ingeniería e Investigación, vol. 36, no. 3, pp. 89-94, 2016.

[20] Y. K. Yang, M. T. Chuang, and S. S. Lin, "Optimization of dry machining parameters for high-purity graphite in end milling process via design of experiments methods," Journal of Materials Processing Technology, vol. 209, no. 9, pp. 43954400, 2009.

[21] J. R. Shie, "Optimization of dry machining parameters for high-purity graphite in end-milling process by artificial neural networks: a case study," Materials and Manufacturing Processes, vol. 21, no. 8, pp. 838-845, 2006.

[22] Y. K. Yang, J. R. Shie, and C. H. Huang, "Optimization of dry machining parameters for high-purity graphite in end-milling process," Materials and Manufacturing Processes, vol. 21, no. 8, pp. 832-837, 2006.

[23] V. Bajpai and R. K. Singh, "Orthogonal micro-grooving of anisotropic pyrolytic carbon," Materials and Manufacturing Processes, vol. 26, no. 12, pp. 1481-1493, 2011.

[24] V. Bajpai and R. K. Singh, "Brittle damage and interlaminar decohesion in orthogonal micromachining of pyrolytic carbon," International Journal of Machine Tools and Manufacture, vol. 64, pp. 20-30, 2013.

[25] B. Lawn and R. Wilshaw, "Review indentation fracture: principles and applications," Journal of Materials Science, vol. 10, no. 6, pp. 1049-1081, 1975.

[26] Z. P. Wan and Y. Tang, "Brittle-ductile mode cutting of glass based on controlling cracks initiation and propagation," International Journal of Advanced Manufacturing Technology, vol. 43, no. 11-12, pp. 1051-1059, 2009.

[27] B. Paul and L. Mirandy, "Improved fracture criterion for three-dimensional stress states," Journal of Engineering Materials and Technology, vol. 98, no. 2, pp. 159-163, 1976. 


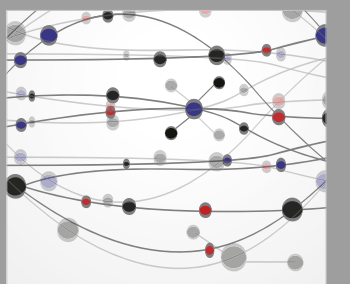

The Scientific World Journal
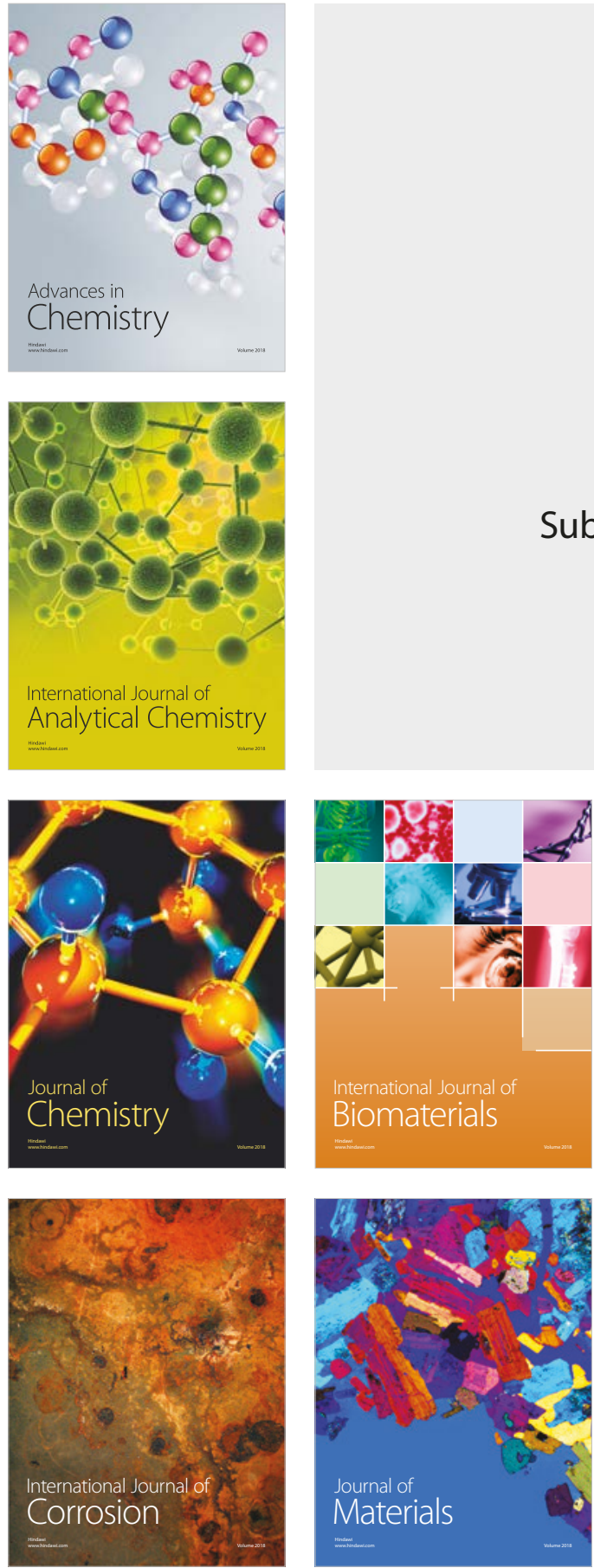

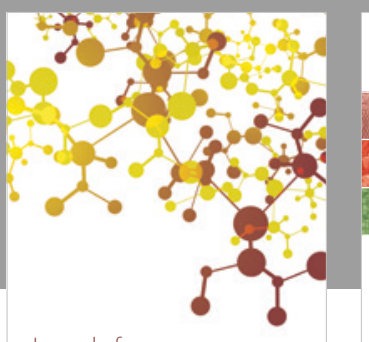

Journal of

Applied Chemistry
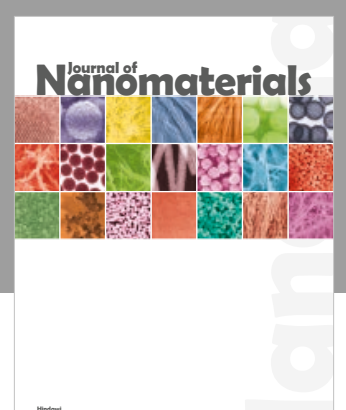

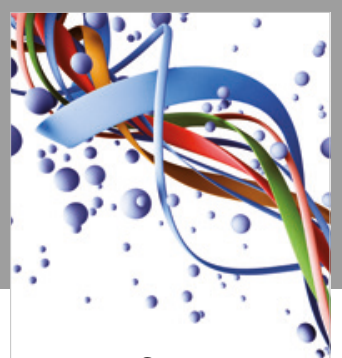

Scientifica

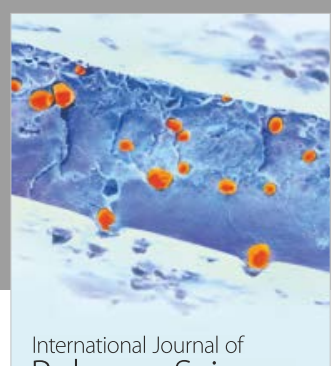

Polymer Science

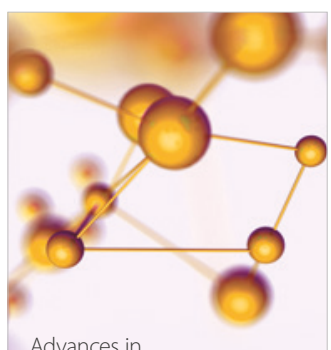

Physical Chemistry
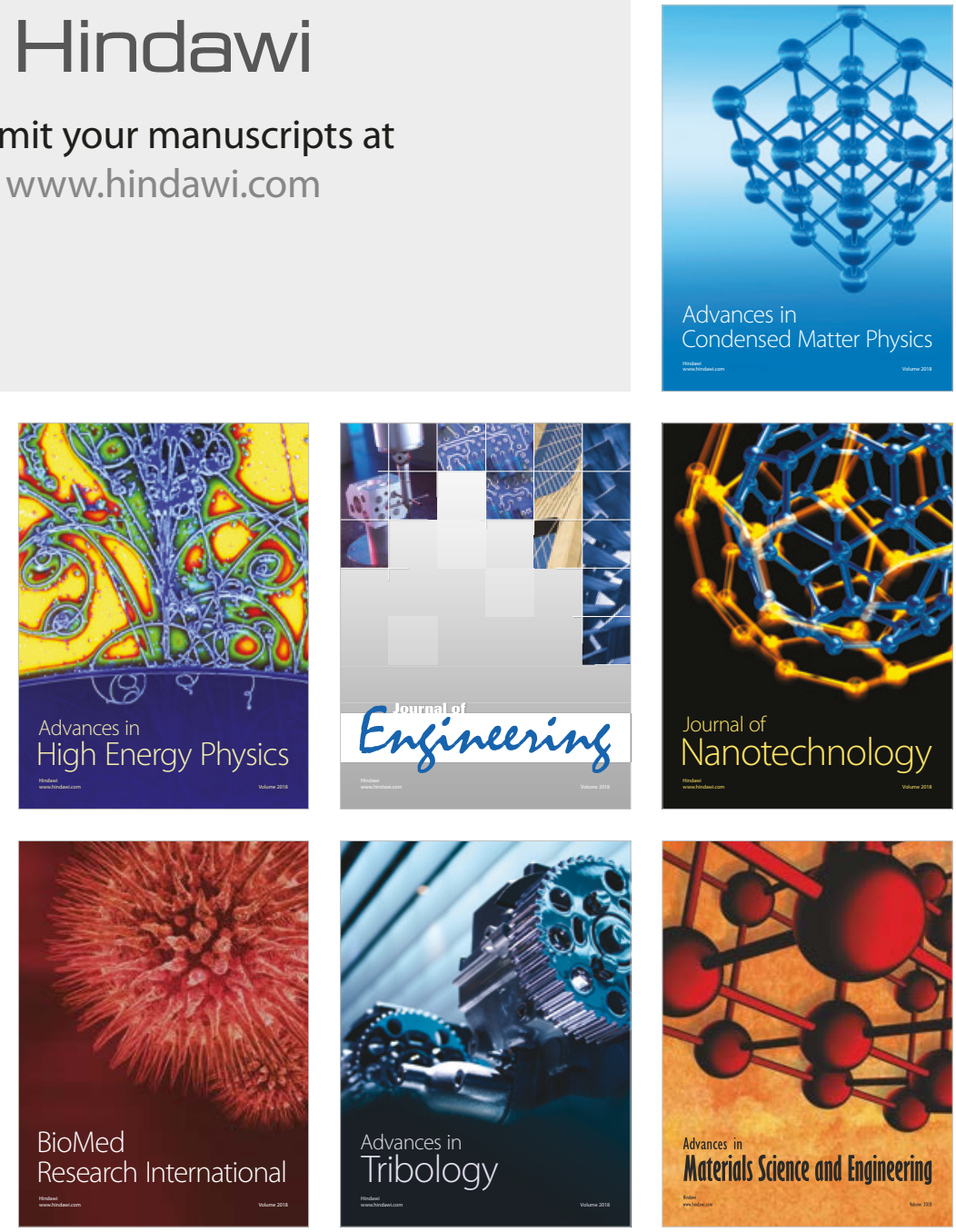